\title{
Neural Mechanisms and Pathways in Craniofacial Pain
}

\author{
Barry J. Sessle
}

\begin{abstract}
Many free nerve endings of small-diameter afferents (A-delta or C nerve fibres) respond to craniofacial noxious stimuli and a number of neurochemicals are involved in their activation or sensitization. The small-diameter nociceptive afferents project to the trigeminal (V) brainstem complex where they can excite nociceptive neurones that have been categorized as either nociceptive-specific (NS) or wide dynamic range (WDR). These neurones project to other brainstem regions or to the contralateral thalamus. The lateral and medial thalamus contain NS and WDR neurones which have properties and connections with the overlying cerebral cortex or other thalamic regions indicative of a role for most of them in the sensory-discriminative, affective or other dimensions of pain. Some of the V brainstem NS and WDR neurones respond exclusively to cutaneous sensory inputs and have features indicating their involvement in acute superficial craniofacial pain. Many of the neurones, however, receive convergent inputs from afferents supplying other craniofacial tissues (e.g. cerebrovascular, muscle) as well as skin, and are likely involved in deep pain, as well as spread and referral that is typically seen in headache and several craniofacial pain conditions involving deep tissues. Convergence may also be an important factor underlying the neuroplastic changes in $\mathrm{V}$ neuronal properties that may occur with peripheral injury or inflammation. These changes include a prolonged enhancement of the cutaneous as well as deep afferent inputs to most NS and WDR neurones and expansion of their cutaneous or deep mechanoreceptive field and increased EMG activity in the jaw musculature. They involve NMDA, non-NMDA and opioid neurochemical mechanisms within peripheral tissues as well as within the CNS. Such modulatory effects on brainstem neuronal properties reflect the functional plasticity of the central $\mathrm{V}$ system, and may be involved in the development of headache and other conditions that manifest craniofacial pain.
\end{abstract}

RÉSUMÉ: Mécanismes et voies nerveuses dans la douleur crâniofaciale. Plusieurs terminaisons nerveuses libres des afférents de petit diamètre (fibres nerveuses A-delta ou C) répondent à des stimuli crâniofaciaux douloureux. Plusieurs substances neurochimiques sont impliquées dans leur activation ou leur sensibilisation. Les afférents nociceptifs de petit diamètre ont des projections au complexe du trijumeau (V) dans le tronc cérébral où ils peuvent exciter les neurones nociceptifs qui ont été classés comme nociceptifs-spécifiques (NS) ou comme ayant un spectre dynamique étendu (WDR). Ces neurones projettent à d'autres régions du tronc cérébral ou au thalamus contralatéral. Le thalamus latéral et médian contient des neurones NS et WDR qui ont des propriétés et des connections avec le cortex cérébral sus-jacent ou avec d'autres régions thalamiques, ce qui indique que la plupart ont un rôle dans les aspects sensitifs-discriminatifs, affectifs ou autres de la douleur. Certains des neurones NS et WDR du complexe V du tronc cérébral répondent exclusivement aux influx sensitifs cutanés et ont des caractéristiques indiquant leur implication dans la douleur crâniofaciale superficielle aiguë. Cependant, plusieurs des neurones reçoivent des influx convergents d'afférents innervant d'autres tissus crâniofaciaux (i.e. tissus cérébrovasculaires, musculaires) ainsi que la peau et sont probablement impliqués dans la douleur profonde, incluant la douleur étendue et référée qui est observée typiquement dans la céphalée et dans plusieurs autres pathologies crâniofaciales douloureuses impliquant les tissus profonds. La convergence pourrait également être un facteur important, sous-jacent aux changements neuroplastiques dans les propriétés nerveuses du complexe $\mathrm{V}$ qui pourraient survenir lors d'un traumatisme périphérique ou de l'inflammation. Ces changements incluent un rehaussement prolongé des influx des afférents cutanés et profonds à la plupart des neurones NS et WDR, une expansion de leur champ mécanoréceptif cutané ou profond et une augmentation de l'activité ÉMG de la musculature de la mâchoire. Ils impliquent des mécanismes neurochimiques NMDA, non-NMDA et opioïdes dans les tissus périphériques ainsi que dans le SNC. De tels effets modulateurs sur les propriétés des neurones du tronc cérébral reflètent la plasticité fonctionnelle du système $\mathrm{V}$ central et peuvent être impliqués dans le développement de la céphalée et d'autres conditions qui se manifestent par de la douleur crâniofaciale.

Can. J. Neurol. Sci. 1999; 26: Suppl. 3-S7-S11

Pain is nowadays conceptualized as a multidimensional experience encompassing sensory-discriminative, cognitive, emotional and motivational dimensions. Many of the difficulties experienced by clinicians with the diagnosis and management of acute and chronic craniofacial pain conditions stem from a lack of recognition and understanding of these factors and from uncertainties of the aetiology or pathogenesis of the conditions. However, considerable advances have been made over the last two decades in our understanding of craniofacial pain mechanisms. This paper reviews recent research that has identified critical neural elements and pathways in the brainstem

From the Faculty of Dentistry, and Department of Physiology, Faculty of Medicine, University of Toronto, Toronto, Ontario, Canada

Reprint requests to: Faculty of Dentistry, University of Toronto, 124 Edward Street, Toronto, Ontario, Canada M5G 1G6 


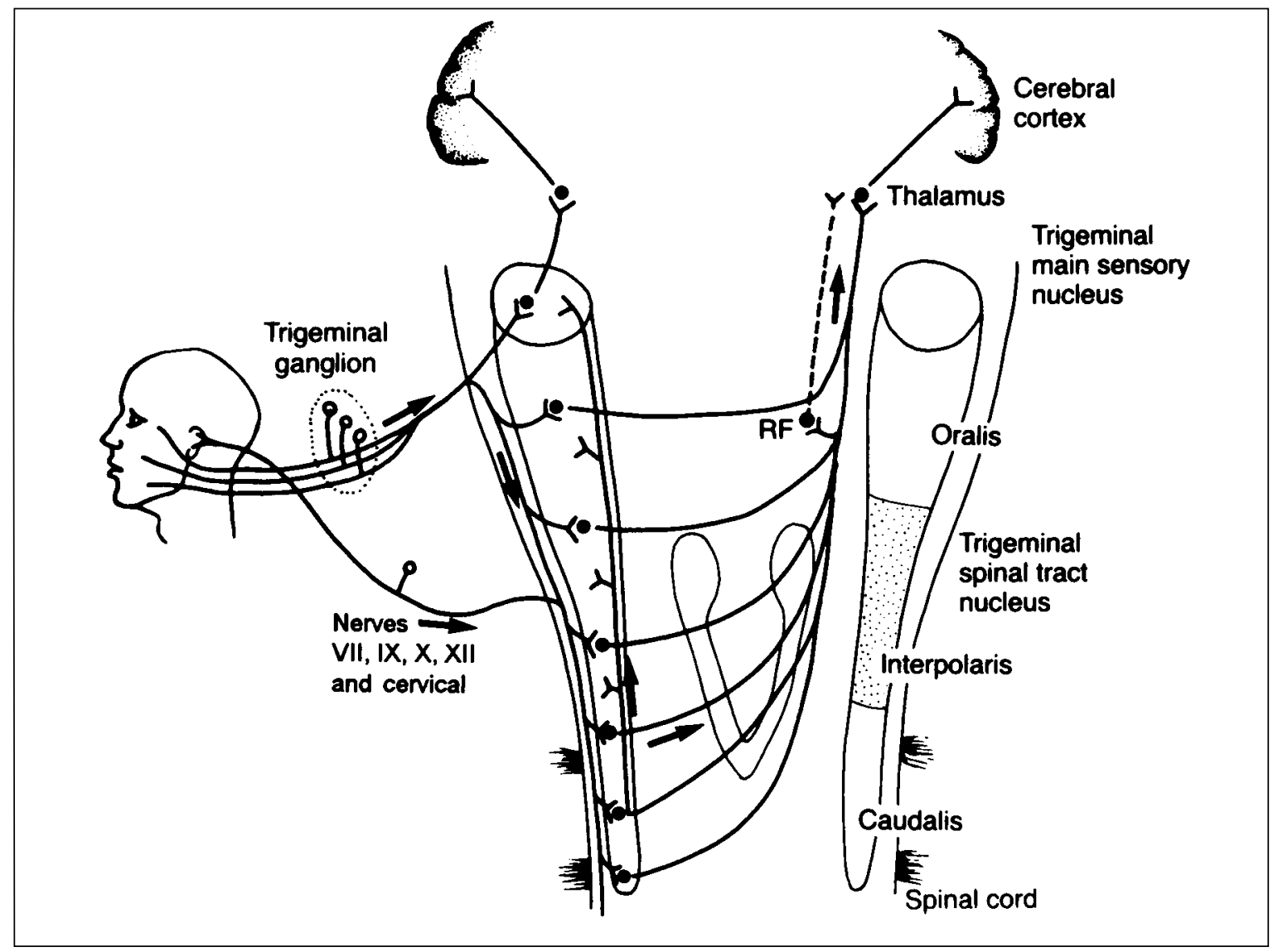

Figure 1. Major pathway transmitting sensory information from the mouth and face. Primary afferents project via the trigeminal ganglion to second-order neurones in the V brainstem complex. These neurones then may project to neurones at higher levels of the CNS (for example, in the thalamus) or in brainstem regions such as the reticular formation (RF) or cranial nerve motor nuclei. Some afferents from cranial nerves VII, IX, X and XII and cervical nerve afferents may also synapse in the $V$ complex as shown, although many VII, IX, and X afferents also relay (not shown) in the solitary tract nucleus (the horseshoeshaped structure in the middle of the diagram). (Modified from Sessle BJ. Temperature, touch, taste, and olfaction. In: Roth GI, Calmes R, eds. Oral Biology. St. Louis: CV Mosby, 1981, p. 39; with permission.)

and higher levels of the trigeminal (V) somatosensory system that receive and transmit nociceptive inputs from craniofacial tissues, as well as some of the mechanisms involved in the modulation and plasticity of craniofacial nociceptive transmission.

\section{Peripheral Mechanisms}

Other papers in this supplement focus on peripheral processes, so only a brief overview of these mechanisms is provided here. Free nerve endings in the craniofacial region provide the peripheral basis for pain: many free nerve endings act as nociceptors, that is they are the sense organs that respond to noxious stimulation of peripheral tissues. Their activation may result in the excitation of the small-diameter (A-delta or $\mathrm{C}$ ) afferent nerve fibres with which they are associated and provide sensory-discriminative information to the brain about the location, quality, intensity and duration of the noxious stimulus. A number of neurochemicals (e.g. substance P, 5-HT) are involved in the activation of these peripheral endings by noxious stimulation or in their peripheral sensitization; the sensitivity of the endings may increase following mild injury, and this sensitization of nociceptive endings is a peripheral mechanism that helps to protect injured tissues from repeated injury. ${ }^{1,2,3}$ Also, nociceptive afferents appear susceptible to sympathetic modulation following injury, and this peripheral modulation is thought to be a factor contributing to certain pain conditions. ${ }^{2,3}$

\section{Brainstem and Thalamocotrical Mechanisms}

The afferents innervating cutaneous, intraoral, deep (e.g. joint, muscle) and cerebrovascular tissues project to the $\mathrm{V}$ brainstem complex. The $\mathrm{V}$ brainstem complex can be subdivided into the main or principal sensory nucleus and the spinal tract nucleus, which comprises three subnuclei: oralis, interpolaris, and caudalis (Figure 1). Based on anatomical, clinical and electrophysiological observations, subnucleus caudalis is usually viewed as the principal brainstem relay site of $\mathrm{V}$ nociceptive information. 1,4,5,6,7 For example, anatomical studies have revealed that the small-diameter afferents carrying nociceptive information from the various craniofacial tissues predominantly terminate in caudalis laminae I, II, and V and VI. Moreover, 
recent immunocytochemical studies of the expression of protooncogenes such as c-fos have revealed that increased c-fos expression occurs in caudalis neurones following noxious stimulation of craniofacial tissues including skin, temporomandibular joint (TMJ), cornea and cerebrovascular tissues. ${ }^{8,9,10,11}$ Furthermore, electrophysiological studies have revealed that many neurones respond to cutaneous nociceptive inputs; these nociceptive neurones have been categorized as either nociceptive-specific (NS) neurones or wide dynamic range (WDR) neurones. ${ }^{1,4,5,6,7}$ The NS neurones respond only to noxious stimuli (e.g. pinch, heat) applied to a localized craniofacial receptive field $(\mathrm{RF})$ and receive small-diameter afferent inputs from A delta and/or $\mathrm{C}$ fibres; WDR neurones are excited by non-noxious (e.g. tactile) stimuli as well as by noxious stimuli, and may receive large-diameter and smalldiameter A-fibre inputs as well as C-fibre inputs. Many NS and WDR neurones in subnucleus caudalis can be excited only by natural stimulation of cutaneous or mucosal tissues and have properties consistent with a role in the detection, localization, and discrimination of superficial noxious stimuli., ${ }^{4,7}$

The majority of NS and WDR neurones can nonetheless also be excited by other types of peripheral afferent inputs such as those from cerebrovascular, tooth pulp, TMJ or muscle tissues. $5,6,7,12,13,14$ The extensive convergent afferent input patterns that are characteristic of TMJ or myofascial-activated NS and WDR neurones in subnucleus caudalis may explain the poor localization of deep pain, as well as contribute to the spread and referral of pain that are typical of deep pain conditions involving the TMJ and associated musculature. The poor localization of pain and the frequent occurrence of pain referral in most toothaches and headaches may also be explained by analogous convergence patterns from tooth pulp and cerebrovascular afferents. For example, most of the neurones in the $\mathrm{V}$ brainstem complex that can be excited by stimulation of cerebrovascular afferents are NS or WDR neurones with a cutaneous RF involving the ophthalmic division; the predominant periorbital RF of these neurones is consistent with the common referral patterns of most vascular cephalic pains to this region of the head. ${ }^{9,12,13}$

Analogous anatomical and physiological features characterize the spinal dorsal horn which is also a laminated structure and which represents the integral component of spinal nociceptive mechanisms. Consequently, subnucleus caudalis is now often termed the 'medullary dorsal horn'. Although a crucial role in craniofacial nociceptive mechanisms has been documented for caudalis, recent studies nonetheless have also implicated the rostral components of the $\mathrm{V}$ brainstem complex such as subnucleus oralis. The relative importance and role in both deep and superficial pain mechanisms of the rostral and caudal components of the $\mathrm{V}$ brainstem complex is nonetheless still unclear. ${ }^{7}$

Neurones at all levels of the $\mathrm{V}$ brainstem complex project to other brainstem regions including the reticular formation and cranial nerve motor nuclei; their connectivity to these particular regions provide the central substrate underlying autonomic and muscle reflex responses to craniofacial stimuli. Many $\mathrm{V}$ brainstem neurones may project to the contralateral thalamus via direct or multisynaptic paths. ${ }^{1,5,6,7}$ The regions of the thalamus that are well known to receive and relay somatosensory information from the craniofacial region are the ventrobasal complex (or ventroposterior nucleus) as well as the so-called posterior group of nuclei, and the medial thalamus. These thalamic regions contain NS and WDR neurones having properties that are generally similar to those described for comparable neurones in the subthalamic relays such as subnucleus caudalis.

The ventrobasal nociceptive neurones have properties and connections with the overlying somatosensory cerebral cortex, indicative of a role for most of them in the sensorydiscriminative dimension of pain. In contrast, nociceptive neurones in the more medial nuclei (e.g. intralaminar nuclei; parafascicular nucleus) are generally considered to have properties and connections (e.g. with anterior cingulate cortex; see below) suggestive of a role more in the affective or motivational dimensions of pain. Neurones have been described in somatosensory cortex with properties indicating a role in localization and intensity coding of noxious thermal facial or tooth pulp stimuli. ${ }^{6,15}$ Nociceptive neurones also occur in other cortical regions, such as the anterior cingulate cortex, which has been implicated in the affective dimension of pain. ${ }^{6,15}$ The significance of these mechanisms to human pain processes is underscored by recent brain imaging findings in humans of activation by noxious stimuli of several cortical regions, including somatosensory cortex and anterior cingulate cortex. ${ }^{16}$

\section{Modulation of Nociceptive Transmission}

Modification of somatosensory transmission can occur at thalamic and cortical neuronal levels, although the modification of ascending somatosensory messages may, in fact, largely occur earlier in the $\mathrm{V}$ pathway, namely in the brainstem. ${ }^{1,7,17}$ The intricate organization of each subdivision of the $\mathrm{V}$ brainstem complex and the variety of inputs to each of them from peripheral tissues or from intrinsic brain regions provide the substrate for numerous interactions between the various inputs. For example, the activity of $\mathrm{V}$ nociceptive brainstem neurones can be modulated (e.g. suppressed) by influences derived from structures within the V brainstem complex itself (e.g. substantia gelatinosa) as well as from other parts of the brainstem and higher centres (e.g. periaqueductal gray, somatosensory cortex) which utilize endogenous neurochemicals such as opioids, 5-HT, or GABA. These modulatory influences are of clinical significance since they have been implicated as intrinsic mechanisms contributing to the analgesic effects of several therapeutic approaches, e.g. deep brain stimulation, acupuncture, and opioid-related drugs. ${ }^{7,17}$

\section{NeUROPLASTICITY}

The properties of nociceptive neurones in the brain can also be modified as a consequence of peripheral nerve injuries as well as by peripheral tissue trauma and inflammatory conditions. Deafferentation of the tooth pulp or other craniofacial sites in the adult animal can, for example, result in physiological, morphological and neurochemical changes in the $\mathrm{V}$ brainstem complex that may last several weeks. ${ }^{5,7}$ Changes can also be induced by algesic chemical or inflammatory-induced afferent inputs. For example, the injection of the inflammatory agent and 
small-fibre irritant mustard oil into the tooth pulp or into deep tissues such as the TMJ or masticatory muscles can lead to expansion of the RF and enhancement of the responses of NS and WDR caudalis and oralis neurones to craniofacial stimuli. ${ }^{14,18,19,20}$ Chemical stimulation of cerebrovascular afferents may also induce comparable neuroplastic changes in $\mathrm{V}$ brainstem neurones. ${ }^{12}$ These mustard oil-induced changes in the $\mathrm{V}$ brainstem complex may be accompanied by reflexly-induced EMG activity in jaw muscles. ${ }^{20,21}$

These neuroplastic changes are remarkable since depending on the stimulus or form of injury or inflammation, they can last for hours or days, even weeks, and are associated with behavioural changes in pain sensitivity. They appear to be due to mechanisms that reflect a "functional plasticity" or "central sensitization" of nociceptive neurones and involvement of the extensive pattern (see above) of convergent afferent inputs to these neurones. ${ }^{7,22,23}$ Both neuropeptide (e.g. substance P) and excitatory amino acid receptor mechanisms appear to be involved in these processes. For example, NMDA and nonNMDA receptor mechanisms underlie the involvement of excitatory amino acids in nociceptive processing, and NMDA receptor mechanisms in particular, appear to be very important in the central sensitization process to the extent that NMDA antagonists might be useful as analgesics, especially in the treatment of persistent pain. ${ }^{22,23}$ Centrally acting NMDA antagonists, for example, are particularly effective in preventing the RF expansion and hyperexcitability of nociceptive neurones in $\mathrm{V}$ subnucleus caudalis or oralis, induced by peripheral inflammatory conditions (e.g. by mustard oil) or by C-fibre strength electrical stimulation of afferent nerves, and in antagonizing the mustard oil-induced reflex enhancement of jaw muscle EMG activity mentioned above. ${ }^{18,20,21}$

In addition to the NMDA and non-NMDA receptor subtypes, several second messenger systems such as nitric oxide and protein kinase $\mathrm{C}$ may also be involved in this central sensitization process. ${ }^{7,22,23}$ Moreover, a central opioid depressive effect may be "triggered" into action by the peripheral injury or inflammation since the intrathecal or systemic administration of the opioid antagonist naloxone can "re-kindle" the jaw muscle EMG activity and neuronal RF changes in caudalis, induced by mustard oil but only if the naloxone is administered in conjunction with the mustard oil. ${ }^{7,20}$ These findings suggest that a nociceptive afferent input to the brain, triggered in this case by the inflammatory irritant mustard oil, evokes neuronal activity in subnucleus caudalis and associated neuromuscular changes, but these neural changes are limited by the recruitment of a central opioid inhibitory mechanism.

Peripheral NMDA, non-NMDA and opioid processes may also be involved in these neurochemical processes contributing to neuroplasticity. For example, jaw muscle activity similar to that evoked by mustard oil can be elicited by glutamate and NMDA and non-NMDA receptor subtype agonists applied locally to the TMJ region, and this activity can be blocked by the local (TMJ) application of specific NMDA or non-NMDA antagonists or morphine. ${ }^{24,25}$ These findings clearly indicate that peripheral, as well as central excitatory amino acid and neuropeptide receptor mechanisms may play a role in the expression of central neuroplasticity in somatosensory and motor pathways.

One final point is the clinical significance of the findings of neuroplasticity in pain pathways. The neuroplastic changes are viewed as important processes underlying the development and maintenance of chronic pain as well as acute pain associated with injury and inflammation. They also underscore the fact that these pathways are not "hard-wired" but are "plastic" and subject to modification by peripherally-induced events and sustained by central as well as peripheral neural changes. Moreover, the neuroplastic mechanisms may be involved in the spread and referral of pain such as may occur in headaches, and they may also contribute to the tenderness and hyperalgesia of superficial tissues that characterize many cases involving injury to deep tissues in the craniofacial region. ${ }^{3,7}$ In addition, the neuromuscular changes noted above may serve to protect the masticatory system from potentially damaging movements and stimuli, and so might be related to clinically based concepts of craniofacial neuromuscular dysfunction. Finally, the emerging knowledge of the peripheral and central neurochemical mechanisms contributing to the neuroplastic changes offer promise of new or improved pharmacological approaches to manage craniofacial pain.

\section{ACKNOWLEDGEMENTS}

The cited studies by the author were supported by grant DE04786 from the US National Institutes of Health and by grant MT4918 from the Canadian Medical Research Council. The secretarial assistance of Ms. Fong Yuen is gratefully acknowledged.

\section{REFERENCES}

1. Dubner R, Storey AT, Sessle BJ. The Neural Basis of Oral and Facial Function. New York: Plenum Press, 1978.

2. Hargreaves KM, Roszkowski MT, Jackson DL, et al. Neuroendocrine and immune response to injury, degeneration, and repair. In: Sessle BJ, Bryant PS, Dionne RA, eds. Temporomandibular Disorders and Related Pain Conditions. Progress in Pain Research and Management, Vol 4. Seattle: IASP Press, 1995: 273-292.

3. Lund JP, Sessle BJ. Neurophysiological mechanisms related to chronic pain disorders of the temporomandibular joint and masticatory muscles. In: Zarb GE, Carlsson G, Sessle BJ, Mohl ND, eds. Temporomandibular Joint and Masticatory Muscle Disorders. Copenhagen: Munksgaard, 1994: 188-207.

4. Dubner R. Recent advances in our understanding of pain. In: Klineberg I, Sessle B, eds. Oro-Facial Pain and Neuromuscular Dysfunction: Mechanisms and Clinical Correlates. Oxford: Pergamon Press, 1985: 3-19.

5. Sessle BJ. The neurobiology of facial and dental pain: present knowledge, future directions. J Dent Res 1987; 66: 962-981.

6. Sessle BJ. Mechanisms of trigeminal and occipital pain. Pain Reviews 1996; 3: 91-116.

7. Sessle, BJ. Acute and chronic craniofacial pain: brainstem mechanisms of nociceptive transmission and neuroplasticity, and their clinical correlates. Crit Rev Oral Biol \& Med, in press, 1999.

8. Hathaway $\mathrm{CB}, \mathrm{Hu} \mathrm{JW}$, Bereiter DA. Distribution of fos-like immunoreactivity in the caudal brainstem of the rat following noxious chemical stimulation of the temporomandibular joint. J Comp Neurol 1995; 356: 444-456.

9. Hoskin KL, Kaube H, Goadsby PJ. Sumatriptan can inhibit trigeminal afferents by an exclusively neural mechanism. Brain 1996; 119: 1419-1428.

10. Nozaki K, Moskowitz MA, Boccalini P. CP-93,129, sumatriptan, dihydroergotamine block c-fos expression within rat trigeminal nucleus caudalis caused by chemical stimulation of the meninges. Br J Pharmacol 1992; 106: 409-415.

11. Shepheard SL, Williamson DJ, Williams J, Hill RG, Hargreaves RJ.

Suppl. 3 - S10 
Comparison of the effects of sumatriptan and the $\mathrm{NK}_{1}$ antagonist CP-99,994 on plasma extravasation in dura mater and c-fos mRNA expression in trigeminal nucleus caudalis of rats. Neuropharmacology 1995; 34: 255-261.

12. Burstein R, Yamamura H, Malick A, Strassman AM. Chemical stimulation of the intracranial dura induces enhanced responses to facial stimulation in brain stem trigeminal neurons. J Neurophysiol 1998; 79: 964-982.

13. Dostrovsky JO, Davis KD, Kawakita K. Central mechanisms of vascular headaches. Can J Physiol Pharmacol 1991; 69: 652-658

14. Sessle BJ, Hu JW, Yu X-M. Brainstem mechanisms of referred pain and hyperalgesia in the orofacial and temporomandibular region. In: Vecchiet L, Albe-Fessard D, Lindblom U, eds. New Trends in Referred Pain and Hyperalgesia. Pain Research and Clinical Management, Vol 7. Amsterdam: Elsevier, 1993: 59-71.

15. Iwata K, Tsuboi Y, Tashiro A, Sakamoto M, Sumino R. Integration of tooth-pulp pain at the level of cerebral cortex. In: Nakamura Y, Sessle BJ, eds. Neurobiology of Mastication - from Molecular to Systems Approach. Amsterdam: Elsevier, 1999, in press.

16. Casey KL, Minoshima S. Can pain be imaged? In: Jensen TS, Turner JA, Wiesenfeld-Hallin Z, eds. Proceedings of the 8th World Congress on Pain. Progress in Pain Research and Management, Vol 8. Seattle: IASP Press, 1997: 855-866.

17. Fields HL, Basbaum AI. Central nervous system mechanisms of pain modulation. In: Wall PD, Melzack R, eds. Textbook of Pain, 3rd ed. London: Churchill Livingstone. 1994: 243-257.

18. Chiang CY, Park SJ, Kwan CL, Hu JW, Sessle BJ. NMDA receptor mechanisms contribute to neuroplasticity induced in caudalis nociceptive neurons by tooth pulp stimulation. J Neurophysiol 1998; 80: 2621-2631.
19. Hu JW, Sessle BJ, Raboisson P, Dallel R, Woda A. Stimulation of craniofacial muscle afferents induces prolonged facilitatory effects in trigeminal nociceptive brainstem neurones. Pain 1992; 48:53-60.

20. $\mathrm{Hu} \mathrm{JW}$, Tsai C-M, Bakke $\mathrm{M}$, et al. Deep craniofacial pain: involvement of trigeminal subnucleus caudalis and its modulation. In: Jensen TS, Turner JA, Wiesenfeld-Hallin Z, eds. Proceedings of the 8th World Congress on Pain. Progress in Pain Research and Management, Vol 8. Seattle: IASP Press, 1997: 497-506.

21. Yu X-M, Sessle BJ, Haas DA, et al. Involvement of NMDA receptor mechanisms in jaw electromyographic activity and plasma extravasation induced by inflammatory irritant application to temporomandibular joint region of rats. Pain 1996; 68: 169-178.

22. Coderre TJ, Katz J. Peripheral and central hyperexcitability: differential signs and symptoms in persistent pain. Behav Brain Sci 1997; 20: 404-419.

23. Dubner R. Spinal cord neuronal plasticity: mechanisms of persistent pain following tissue damage and nerve injury. In: Vecchiet L, Albe-Fessard D, Lindblom U, eds. New Trends in Referred Pain and Hyperalgesia. Pain Research and Clinical Management, Vol 7. Amsterdam: Elsevier, 1993: 109-117.

24. Bakke M, Hu JW, Sessle BJ. Morphine application to peripheral tissues modulates nociceptive jaw reflex. NeuroReport 1998; 9: 3315-3319.

25. Cairns BE, Sessle BJ, Hu JW. Evidence that excitatory amino acid receptors within the temporomandibular joint region are involved in the reflex activation of the jaw muscles. J Neurosci 1998; 18: 8056-8064. 